\title{
Reliability and validity of rehabilitative ultrasound images obtained using a hands-free fixed probe in measuring the muscle structures of the tibialis anterior and the gastrocnemius
}

\author{
Mun-Sang Choi ${ }^{a}$, Jang-Hoon Shin ${ }^{b}$, Hye-Kang Park ${ }^{b}$, Wan-Hee Lee ${ }^{c}$

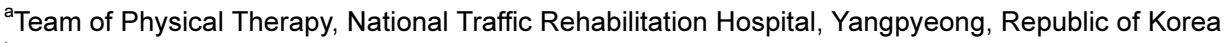 \\ ${ }^{\mathrm{b}}$ Department of Physical Therapy, The Graduate School, Sahmyook University, Seoul, Republic of Korea \\ 'Department of Physical Therapy, College of Health Science and Social Welfare, Sahmyook University, Seoul, Republic of Korea
}

\begin{abstract}
Objective: This study aimed to investigate the reliability and validity of muscle thickness (MT) and pennation angle (PA) measurements of the ankle muscle, including the tibialis anterior (TA) and the medial gastrocnemius (MGCM), using a hands-free fixed probe and to compare it with the conventional linear probe.

Design: Observational inter-rater reliability study.

Methods: Thirty-three healthy subjects (20 male, 13 female) were included. In all subjects, ultrasound images were acquired from the TA and MGCM using a hands-free fixed probe and a conventional linear probe in random sequence by two examiners at two time-points within a 7-day interval. MT and PA were calculated on the taken images. Intra-class correlation coefficients (ICC), 95\% confidence intervals, standard error of measurement and the Pearson's correlation coefficient were used to estimate reliability and validity. And also, Bland-Altman plots were generated for a visual representation of MT and PA at the TA and MGCM.

Results: The ICC for all intra-rater reliability was 0.943 to 0.995 and that for all inter-rater reliability was 0.928 to 0.993 , indicating excellent reliability. A significantly high correlation was observed between MT and PA at the TA and MGCM with use of the hands-free fixed probe and the conventional linear probe $(r>0.938 ; p<0.001)$.

Conclusions: The hands-free fixed probe provided excellent images for measurement of the MT and PA of the TA and MGCM and is a useful device for making clinical measurements of muscle structure without grasping of the probe.
\end{abstract}

Key Words: Ankle, Muscle structure, Reliability, Ultrasonography, Ultrasound probe

\section{Introduction}

Excessive muscle co-contraction between the tibialis anterior (TA) and the gastrocnemius (GCM) causes stiffness in the ankle joint and limits postural control [1]. The TA provides a peripheral feedback mechanism modulating agonists such as the GCM in maintaining human upright posture and activates reciprocal inhibition that is more likely to be effective for ankle strategy [2]. Young age and healthy status of individuals increases the frequency of using the ankle strat- egy to maintain posture stability [3,4]. This means they use more reciprocal inhibition by the TA on the GCM, which produces less muscle co-contraction in the ankle joint. Ankle movement is the primary maneuver after perturbation in which muscle contraction at the ankle produces a torque that rotates the body toward the support surface [5]. The location of the center of pressure under each foot provides neutral control of the ankle muscles, including the dorsiflexors and plantarflexors that regulate the body's center of gravity, which controls inverted pendulum during static

Received: 28 November, 2019 Revised: 10 December, 2019 Accepted: 12 December, 2019

Corresponding author: Wan-Hee Lee (ORCID https://orcid.org/0000-0001-8030-4853)

Department of Physical Therapy, College of Health Science, Sahmyook University, 815 Hwarang-ro, Nowon-gu, Seoul 01795, Republic of Korea Tel: 82-2-3399-1633 Fax: 82-2-3399-1639 E-mail: whlee@syu.ac.kr

(c) This is an Open-Access article distributed under the terms of the Creative Commons Attribution Non-Commercial License (http://creativecommons.org/licenses/ by-nc/4.0) which permits unrestricted non-commercial use, distribution, and reproduction in any medium, provided the original work is properly cited.

Copyright (๑ 2019 Korean Academy of Physical Therapy Rehabilitation Science 
standing or anterior-posterior small perturbation [6]. Therefore, having control of the ankle muscles is important when implementing the ankle strategy.

Studies have reported that strengthening exercises of the ankle muscles or training can improve or reinforce ankle strategy, and evaluation methods such as magnetic resonance image (MRI) or ultrasound imaging system are useful in assessing changes in muscle function [7-9]. In functional movement of the human body, the structure-function relationship of the muscle is an influencing factor of its function [10], and evaluation of muscle structure is useful to confirm if ankle strategy is appropriate or effective in postural control during standing. As compared to MRI, ultrasound imaging is more convenient, cost-effective, and easy to use in evaluation of muscle function, and physical therapists consider it to be more user friendly. In addition, MRI can't be applied during more dynamic situations such as movement by muscle contraction. Ultrasound imaging system provides high quality images of muscle structure including variables of muscle thickness (MT), pennation angle (PA), fascicle length and cross-sectional area [11-13], and can be used during clinical intervention for visual feedback to improve performance [14-16]. Recently introduced personal computerbased ultrasonography devices have promoted lower-cost ultrasound imaging $[17,18]$.

For measurement or intervention with ultrasound imaging system, examiners commonly use the conventional linear probe but need to grasp the probe continuously during image acquisition; moreover, majority of subjects undergoing ultrasound imaging need to maintain in static positions during the examination period. Due to these limiting factors, examiners face difficulty in obtaining measurement values and visual feedback under dynamic functional movements of the patient such as reaching, sit-to-stand position, and walking, and generally have to fix the probe to the limbs and trunk based on arbitrary estimation. Previous reports have indicated a method of using tape or a device to fix the conventional linear probe to the body for a hands-free approach [19-21]; however, to equip or fit the device to the conventional linear probe requires added time and higher cost.

Recently, in order to address the disadvantages of the conventional linear probe, a hands-free fixed probe was developed with hooks attached on the posterior part that can be linked to a strap for fixation to the body, a design that is different from the hands-free probe. As compared to the handsfree probe, the hands-free fixed probe has the advantage of allowing the examiner to perform the imaging technique without having to hold the probe and to obtain constant ultrasound image with less effort despite the patient's dynamic movement. This study aimed to investigate the reliability and validity of the MT and PA measurements of the ankle muscles, including the TA and medial gastrocnemius (MGCM), by use of a hands-free fixed probe and to compare with the conventional linear probe.

\section{Methods}

\section{Participants}

In this study, 33 healthy individuals ( 20 male, 13 female) were recruited. The sample size of the study was calculated by G*Power for Windows software (Free download version 3.1.9.4, Universitat Kiel, Kiel, Germany) with effect size 0.5 and power 0.8 . The selection criterion for the subjects was no presence of musculoskeletal pain and having normal range of motion in the lower limbs. The exclusion criteria included musculoskeletal pain, limitation of motion in the lower limbs, and neuromuscular dysfunction due to damage of the central or peripheral nerve system. The study was approved by the Institutional Review Board of Sahmyook University, Seoul (IRB No. SYUIRB 2-7001793- AB-N012019049HR).

\section{Procedures}

MT and PA were measured by using a hands-free fixed probe and conventional linear probe with a personal computer-based muscle viewer (PC-BMW) (MicrUs EXT-1H; TELEMED, Vilnius, Lithuania) [13,17]. Images were acquired with both a hands-free fixed probe and a conventional linear probe at $12 \mathrm{MHz}$. The hands-free fixed probe is designed with hooks that can link to the strap that wraps around the limbs; the strap allows the probe to be attached to the body and prevents movement during the measurement process (Figure 1). The location of the probe was standardized in all measurements as follows: the location for the TA was marked at $1 / 3$ rd of the distance from the inferior border of the patella to the lateral malleolus (Figure 1B) [22]; the location for the MGCM was marked at $30 \%$ of the distance from the popliteal crease to the midpoint of the lateral malleolus (Figure 1C) [23]. For assessment of the TA, the subject was placed in supine position on a table with the feet hanging over the edge and neutral position of the hip joint with knee extension. For image acquisition under rest and muscle contraction, subjects were asked to relax their ankle and then perform maximal voluntary contraction. All measurements 

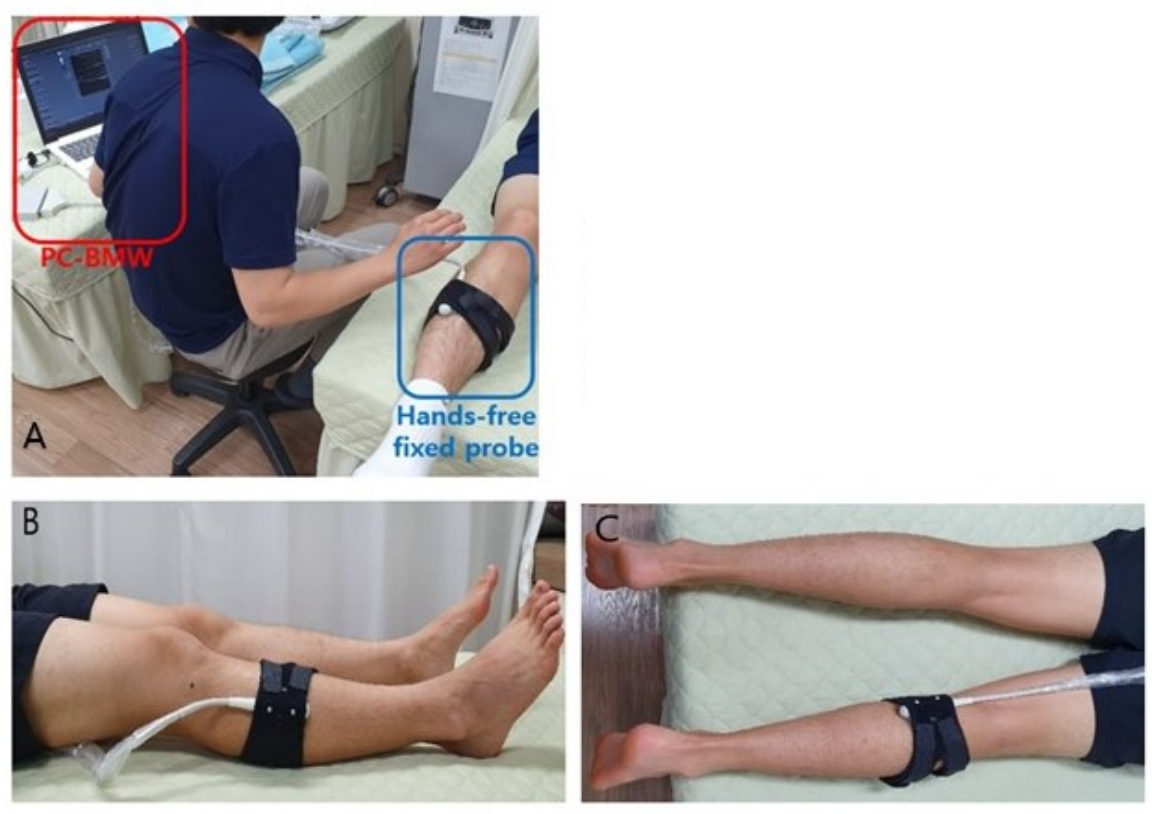

Figure 1. (A) Measuring muscle structure using a hands-free fixed probe linked to PC-BMW. The location of the hands-free fixed probe for (B) tibialis anterior and (C) medial gastrocnemius.

Figure 2. Ultrasound image of muscle thickness (MT) and pennation angle (PA) at (A) tibialis anterior and (B) medial gastrocnemius. were performed three times with each condition. For assessment of the MGCM, the subject was placed in prone position, and the same protocol as in the TA was applied.

The image was captured when muscle architecture such as the aponeuroses or the PA was clearly distinguishable on the monitor. To calculate the muscle structure of the TA, MT was measured between the superficial and deep aponeuroses, and PA was measured between the muscle fascicles and middle aponeurosis (Figure 2A) [22]. In addition, at the MGCM, MT was measured between the superficial and deep aponeuroses, and PA was measured between the muscle fascicles and the deep aponeurosis (Figure 2B) [23]. Image calculation including MT and PA was performed us- ing the PC-BMW with a proprietary software (Echo wave II ver. 3.7.1). All measurements were performed by two examiners with two probes on 2 separate days at an interval of 7 days.

\section{Statistical analysis}

For descriptive statistics, all demographic data were analyzed. To describe the intra- and inter-rater reliability of the MT and PA of the TA and MGCM during rest and contraction, intra-class correlation coefficients (ICC) and $95 \%$ confidence intervals (CI) were calculated. ICC of $<0.50$ was considered as poor, 0.50 to 0.75 as moderate to good, and $>0.75$ as excellent reliability [24]. The standard error of measure- 
ment (SEM) was calculated using the formula: standard deviation $\times \sqrt{1-\text { ICC }}$ based on the reliability coefficients. Bland-Altman plots were generated for visual representation of the MT and PA at the TA and MGCM. To investigate the linear relationship between the hands-free fixed probe and conventional linear probe, the Pearson's correlation coefficient $(r)$ and $r^{2}$ were used. Statistical analysis was performed using the IBM SPSS Statistics for Windows, Version 21.0 (IBM Co., Armonk, NY, USA).

\section{Results}

\section{Demographic characteristics}

Participant characteristics were as follows: Thirty-tree healthy participants (20 male individuals and 13 female individuals) with mean age of $22.00 \pm 2.75$ years were noted; the mean height was $169.90 \pm 8.70 \mathrm{~cm}$; the mean weight was $62.78 \pm 10.38 \mathrm{~kg}$; the mean body mass index was $21.64 \pm 2.28$ $\mathrm{kg} / \mathrm{m}^{2}$ (Table 1).

\section{Intra-rater reliability analysis}

Intra-rater reliability data of the MT and PA for the TA and MGCM by two raters at two sessions is shown in Table 2. For the TA, the ICC (95\% CI) of MT was 0.991-0.995 (0.942$0.997)$, and that of PA was 0.973-0.995 (0.945-0.997). For the MGCM, ICC (95\% CI) of MT was 0.943-0.992 (0.885$0.996)$, and that of PA was 0.968-0.994 (0.935-0.0.997).
Table 1. Demographic characteristics

\begin{tabular}{lc}
\multicolumn{1}{c}{ Characteristics } & Value \\
\hline Sex (female/male) & $13 / 20$ \\
Age $(\mathrm{y})$ & $22.00(2.75)$ \\
Height $(\mathrm{cm})$ & $169.90(8.70)$ \\
Weight $(\mathrm{kg})$ & $62.78(10.38)$ \\
Body mass index $\left(\mathrm{kg} / \mathrm{m}^{2}\right)$ & $21.64(2.28)$ \\
Dominant side $($ left $/$ right $)$ & $2 / 31$ \\
\hline
\end{tabular}

Values are presented as number only or mean (SD)

Table 2. Intra-rater reliability between repeated measures on the conventional linear probe and hands-free fixed probe for TA \& GCM MT and PA (2 days unit: $\left.\mathrm{mm} /{ }^{\circ}\right)$

\begin{tabular}{|c|c|c|c|c|c|c|c|c|c|c|}
\hline \multirow{2}{*}{ Examiner } & \multicolumn{5}{|c|}{ TA (MT/PA) } & \multicolumn{5}{|c|}{ MGCM (MT/PA) } \\
\hline & $\mathrm{CP}$ & HP & ICC & $95 \% \mathrm{CI}$ & SEM & $\mathrm{CP}$ & HP & $\mathrm{ICC}$ & $95 \% \mathrm{CI}$ & SEM \\
\hline \multicolumn{11}{|l|}{1 st day } \\
\hline \multicolumn{11}{|l|}{ E1 } \\
\hline $\mathrm{R}$ & $\begin{array}{c}25.23(3.42) / \\
8.63(2.54)\end{array}$ & $\begin{array}{c}24.86(3.37) / \\
8.86(2.34)\end{array}$ & $\begin{array}{l}0.991 / \\
0.988\end{array}$ & $\begin{array}{c}0.983-0.996 / \\
0.976-0.994\end{array}$ & $\begin{array}{l}0.320 / \\
0.266\end{array}$ & $\begin{array}{l}14.52(2.88) / \\
16.74(5.74)\end{array}$ & $\begin{array}{l}15.27(2.75) / \\
17.73(5.17)\end{array}$ & $\begin{array}{l}0.982 / \\
0.977\end{array}$ & $\begin{array}{c}0.964-0.983 / \\
0.953-0.988\end{array}$ & $\begin{array}{l}0.379 / \\
0.826\end{array}$ \\
\hline $\mathrm{C}$ & $\begin{array}{c}28.40(3.81) / \\
15.93(4.37)\end{array}$ & $\begin{array}{c}26.84(4.20) / \\
15.69(5.05)\end{array}$ & $\begin{array}{l}0.971 / \\
0.988\end{array}$ & $\begin{array}{c}0.942-0.986 / \\
0.975-0.994\end{array}$ & $\begin{array}{l}0.691 / \\
0.545\end{array}$ & $\begin{array}{l}15.82(2.93) / \\
33.33(9.41)\end{array}$ & $\begin{array}{l}15.31(2.64) / \\
32.72(8.99)\end{array}$ & $\begin{array}{l}0.972 / \\
0.968\end{array}$ & $\begin{array}{c}0.944-0.986 / \\
0.935-0.984\end{array}$ & $\begin{array}{l}0.466 / \\
1.634\end{array}$ \\
\hline \multicolumn{11}{|l|}{ E2 } \\
\hline $\mathrm{R}$ & $\begin{array}{c}24.56(3.66) / \\
8.96(2.17)\end{array}$ & $\begin{array}{c}25.47(3.63) / \\
8.85(2.13)\end{array}$ & $\begin{array}{l}0.992 / \\
0.995\end{array}$ & $\begin{array}{c}0.985-0.996 / \\
0.989-0.997\end{array}$ & $\begin{array}{l}0.326 / \\
0.151\end{array}$ & $\begin{array}{l}14.00(2.77) / \\
17.40(3.44)\end{array}$ & $\begin{array}{l}14.81(2.66) / \\
18.72(3.33)\end{array}$ & $\begin{array}{l}0.991 / \\
0.991\end{array}$ & $\begin{array}{c}0.982-0.996 / \\
0.981-0.995\end{array}$ & $\begin{array}{l}0.259 / \\
0.325\end{array}$ \\
\hline $\mathrm{C}$ & $\begin{array}{c}28.05(4.11) / \\
15.07(3.73)\end{array}$ & $\begin{array}{c}27.32(3.66) / \\
14.00(4.01)\end{array}$ & $\begin{array}{l}0.984 / \\
0.986\end{array}$ & $\begin{array}{c}0.967-0.992 / \\
0.971-0.993\end{array}$ & $\begin{array}{l}0.490 / \\
0.459\end{array}$ & $\begin{array}{l}15.40(3.07) / \\
30.84(8.29)\end{array}$ & $\begin{array}{l}14.86(2.72) / \\
30.78(6.42)\end{array}$ & $\begin{array}{l}0.988 / \\
0.973\end{array}$ & $\begin{array}{c}0.975-0.994 / \\
0.945-0.987\end{array}$ & $\begin{array}{l}0.917 / \\
1.209\end{array}$ \\
\hline \multicolumn{11}{|l|}{ 2nd day } \\
\hline $\mathrm{R}$ & $\begin{array}{c}25.48(4.09) / \\
8.88(2.73)\end{array}$ & $\begin{array}{c}26.14(3.57) / \\
8.67(2.21)\end{array}$ & $\begin{array}{l}0.990 / \\
0.973\end{array}$ & $\begin{array}{c}0.980-0.995 / \\
0.945-0.987\end{array}$ & $\begin{array}{l}0.383 / \\
0.405\end{array}$ & $\begin{array}{l}14.89(2.90) / \\
18.29(3.62)\end{array}$ & $\begin{array}{l}14.84(2.77) / \\
18.05(4.67)\end{array}$ & $\begin{array}{l}0.981 / \\
0.979\end{array}$ & $\begin{array}{c}0.961-0.991 / \\
0.957-0.989\end{array}$ & $\begin{array}{l}0.388 / \\
0.602\end{array}$ \\
\hline $\mathrm{C}$ & $\begin{array}{c}28.63(3.92) / \\
16.59(5.10)\end{array}$ & $\begin{array}{c}26.99(3.69) / \\
16.43(4.93)\end{array}$ & $\begin{array}{l}0.995 / \\
0.982\end{array}$ & $\begin{array}{c}0.989-0.997 / \\
0.963-0.991\end{array}$ & $\begin{array}{l}0.273 / \\
0.668\end{array}$ & $\begin{array}{l}15.72(3.40) / \\
33.76(8.93)\end{array}$ & $\begin{array}{l}15.19(3.85) / \\
31.79(9.66)\end{array}$ & $\begin{array}{l}0.943 / \\
0.994\end{array}$ & $\begin{array}{c}0.885-0.972 / \\
0.988-0.997\end{array}$ & $\begin{array}{l}0.498 / \\
0.719\end{array}$ \\
\hline \multicolumn{11}{|l|}{ E2 } \\
\hline $\mathrm{R}$ & $\begin{array}{c}24.83(4.16) / \\
8.62(2.45)\end{array}$ & $\begin{array}{c}25.84(4.00) / \\
8.87(2.32)\end{array}$ & $\begin{array}{l}0.994 / \\
0.975\end{array}$ & $\begin{array}{c}0.989-0.997 / \\
0.950-0.988\end{array}$ & $\begin{array}{l}0.316 / \\
0.375\end{array}$ & $\begin{array}{l}13.45(2.69) / \\
15.75(3.65)\end{array}$ & $\begin{array}{l}14.60(2.91) / \\
17.16(4.68)\end{array}$ & $\begin{array}{c}0.984 / \\
0.981\end{array}$ & $\begin{array}{c}0.967-0.992 / \\
0.961-0.990\end{array}$ & $\begin{array}{l}0.360 / \\
0.567\end{array}$ \\
\hline $\mathrm{C}$ & $\begin{array}{c}27.63(4.33) / \\
15.39(3.67)\end{array}$ & $\begin{array}{c}27.42(3.68) / \\
14.44(3.32)\end{array}$ & $\begin{array}{l}0.984 / \\
0.982\end{array}$ & $\begin{array}{c}0.968-0.992 / \\
0.963-0.991\end{array}$ & $\begin{array}{c}0.504 / \\
0.470\end{array}$ & $\begin{array}{l}14.88(3.07) / \\
28.39(7.11)\end{array}$ & $\begin{array}{l}15.15(3.20) / \\
29.50(6.64)\end{array}$ & $\begin{array}{l}0.992 / \\
0.994\end{array}$ & $\begin{array}{c}0.984-0.996 / \\
0.988-0.997\end{array}$ & $\begin{array}{c}0.279 / \\
0.530\end{array}$ \\
\hline
\end{tabular}

Values are presented as mean (SD).

TA: tibialis anterior, MGCM: medial gastrocnemius, MT: muscle thickness, PA: pennation angle, CP: conventional linear probe, HP: hands-free fixed probe, ICC: intra-class correlation coefficient, CI: confidence interval, SEM: standard error of the mean, E1: examiner 1, E2: examiner 2, $\mathrm{R}$ : rest, C: contraction. 
Table 3. Inter-rater reliability between repeated measures on hands-free fixed probe and the conventional linear probe for TA \& GCM MT and PA (unit: $\mathrm{mm} /{ }^{\circ}$ )

\begin{tabular}{|c|c|c|c|c|c|c|c|c|c|c|}
\hline \multirow{2}{*}{ Probe } & \multicolumn{5}{|c|}{ TA (MT/PA) } & \multicolumn{5}{|c|}{ MGCM (MT/PA) } \\
\hline & E1 & E2 & ICC & $95 \% \mathrm{CI}$ & SEM & E1 & E2 & ICC & $95 \% \mathrm{CI}$ & SEM \\
\hline \multicolumn{11}{|l|}{ HP } \\
\hline $\mathrm{R}$ & $\begin{array}{c}24.86(3.37) / \\
8.86(2.34)\end{array}$ & $\begin{array}{c}25.47(3.63) / \\
8.85(2.13)\end{array}$ & $\begin{array}{c}0.991 / \\
0.988\end{array}$ & $\begin{array}{c}0.981-0.995 / \\
0.975-0.994\end{array}$ & $\begin{array}{c}0.331 / \\
0.243\end{array}$ & $\begin{array}{c}15.27(2.75) / \\
17.73(5.17)\end{array}$ & $\begin{array}{c}14.81(2.66) / \\
18.72(3.33)\end{array}$ & $\begin{array}{c}0.985 / \\
0.940\end{array}$ & $\begin{array}{c}0.970-0.993 / \\
0.879-0.970\end{array}$ & $\begin{array}{l}0.330 / \\
1.065\end{array}$ \\
\hline $\mathrm{C}$ & $\begin{array}{c}26.84(4.20) / \\
15.63(5.05)\end{array}$ & $\begin{array}{c}27.32(3.66) / \\
14.00(4.01)\end{array}$ & $\begin{array}{l}0.962 / \\
0.965\end{array}$ & $\begin{array}{c}0.922-0.981 / \\
0.929-0.983\end{array}$ & $\begin{array}{c}0.764 / \\
0.860\end{array}$ & $\begin{array}{l}15.31(2.64) / \\
32.72(8.99)\end{array}$ & $\begin{array}{l}14.86(2.72) / \\
30.78(6.42)\end{array}$ & $\begin{array}{c}0.992 / \\
0.959\end{array}$ & $\begin{array}{c}0.983-0.996 / \\
0.918-0.980\end{array}$ & $\begin{array}{l}0.239 / \\
1.582\end{array}$ \\
\hline \multicolumn{11}{|l|}{$\mathrm{CP}$} \\
\hline $\mathrm{R}$ & $\begin{array}{c}25.23(3.42) / \\
8.63(2.54)\end{array}$ & $\begin{array}{c}24.56(3.66) / \\
8.96(2.17)\end{array}$ & $\begin{array}{c}0.993 / \\
0.984\end{array}$ & $\begin{array}{c}0.986-0.997 / \\
0.968-0.992\end{array}$ & $\begin{array}{c}0.295 / \\
0.298\end{array}$ & $\begin{array}{l}14.52(2.88) / \\
16.74(5.74)\end{array}$ & $\begin{array}{c}14.00(2.77) / \\
17.40(3.44)\end{array}$ & $\begin{array}{c}0.968 / \\
0.928\end{array}$ & $\begin{array}{c}0.967-0.992 / \\
0.854-0.964\end{array}$ & $\begin{array}{l}0.505 / \\
1.264\end{array}$ \\
\hline $\mathrm{C}$ & $\begin{array}{c}28.40(3.81) / \\
15.93(4.37)\end{array}$ & $\begin{array}{c}28.05(4.11) / \\
15.07(3.73)\end{array}$ & $\begin{array}{l}0.992 / \\
0.982\end{array}$ & $\begin{array}{c}0.983-0.996 / \\
0.965-0.991\end{array}$ & $\begin{array}{c}0.352 / \\
0.544\end{array}$ & $\begin{array}{l}15.82(2.93) / \\
33.33(9.41)\end{array}$ & $\begin{array}{l}15.40(3.07) / \\
30.84(8.29)\end{array}$ & $\begin{array}{c}0.993 / \\
0.967\end{array}$ & $\begin{array}{c}0.986-0.997 / \\
0.932-0.983\end{array}$ & $\begin{array}{l}0.250 / \\
1.614\end{array}$ \\
\hline
\end{tabular}

Values are presented as mean $(\mathrm{SD})$.

TA: tibialis anterior, MGCM: medial gastrocnemius, MT: muscle thickness, PA: pennation angle, E1: examiner 1, E2: examiner 2, ICC: intra-class correlation coefficient, CI: confidence interval, SEM: standard error of the mean, HP: hands-free fixed probe, CP: conventional linear probe, R: rest, C: contraction.

SEM of the TA was 0.151-0.691, and that of the MGCM was 0.259-1.634.

\section{Inter-rater reliability analysis}

For the TA, ICC $(95 \% \mathrm{CI})$ for all measures was $0.952-$ 0.997 (0.922-0.997), and SEM was 0.243-0.860. For the MGCM, ICC (95\% CI) was 0.928-0.993 (0.879-0.996), and SEM was 0.239-1.614 (Table 3). Bland-Altman plots for inter-rater reliability between the two examiners (E1 and E2) are shown in Figure 3.

\section{Correlation between MT and PA taken from two probes}

Good correlation was observed among the hands-free fixed probe and conventional linear probe measurement values of MT and PA $(r>0.938 ; p<0.001)$ by E1 and E2 (Table 4$)$.

\section{Discussion}

In ultrasound imaging to assess muscle structure or provide visual feedback, examiners usually use a hand-held conventional linear probe with continuous manual grasp to obtain consistent images during the measurement period, which is a disadvantage that limits functional evaluation of the muscle during dynamic performance or voluntary movement; the hands-free fixed probe was developed to overcome this limitation. As compared to the hands-free probe, the special design of the hands-free fixed probe contributes to rapid and cost-effective equipping of the device or fitting to the conventional linear probe. Therefore, in this study, we determined the reliability and validity of the measurements made by use of a hands-free fixed probe versus a conventional linear probe. Our results showed that the ICC for all intra-rater reliability of 0.943 to 0.995 was obtained and that for all inter-rater reliability of 0.928 to 0.993 were obtained, indicating excellent reliability. A significantly high correlation was observed between MT and PA of the TA and MGCM assessed by the hands-free fixed probe and conventional linear probe $(r>0.938 ; p<0.001)$.

In this study, MT and PA measurements of the TA assessed by the hands-free fixed probe achieved excellent intra-rater reliability (ICC of TA MT: E1=0.990-0.995 and $\mathrm{E} 2=0.984-0.994$; ICC of PA: $\mathrm{E} 1=0.973-0.988$ and E2 $=0.975-$ 0.995; SEM range: $0.273-0.691 \mathrm{~mm}$ and $0.151 \mathrm{o}-0.668 \mathrm{o}$, respectively) and inter-rater reliability (ICC of MT: 0.9620.992; ICC of PA: 0.965-0.988). McCreesh and Egan [25] reported that with ultrasound, the TA MT using a conventional linear probe achieved excellent inter-rater reliability (ICC [95\% CI]: 0.992-0.997 [0.981-0.998]), with no difference between longitudinal and transverse measurement values. In our study, we obtained longitudinal measurement values of the TA because those images clearly differentiate the landmarks of the aponeuroses in the image analysis, which enabled calculation of both PA and MT and excellent reliability of both MT and PA at the TA. 


\section{Tibialis anterior}
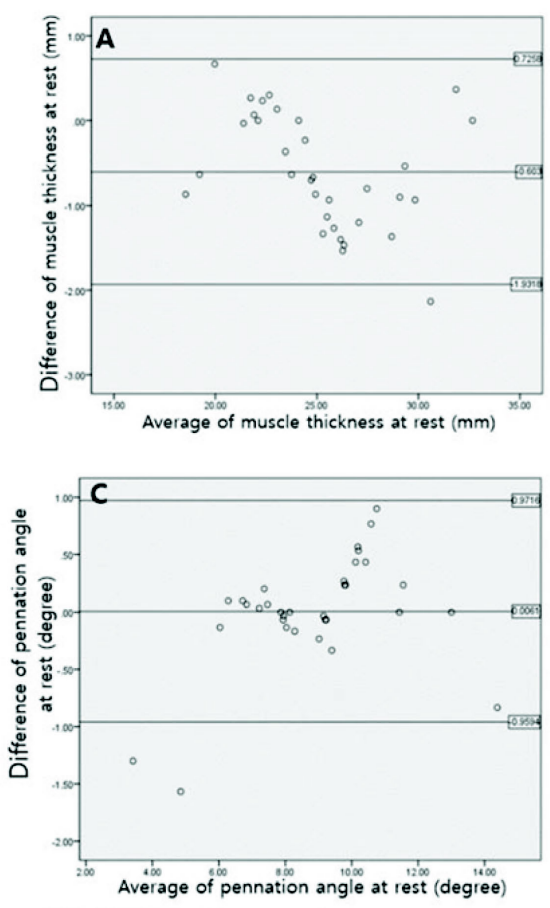

Medial Gastrocnemius
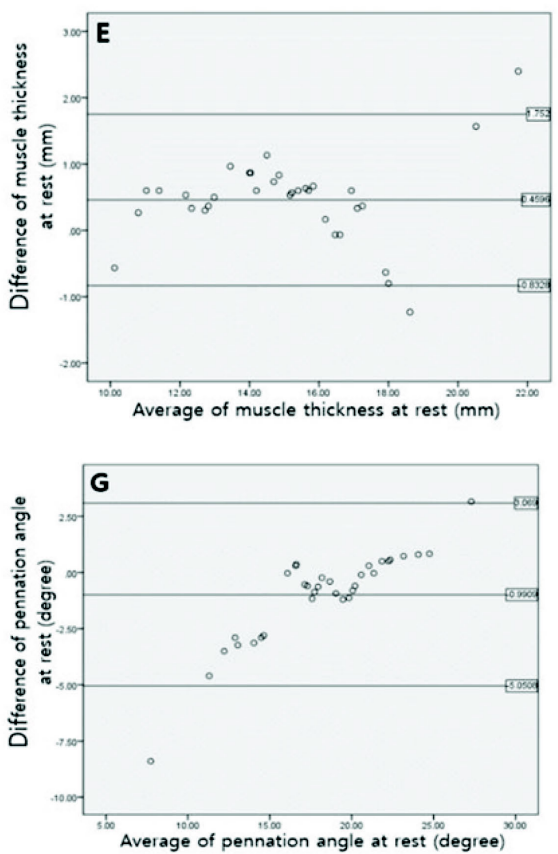
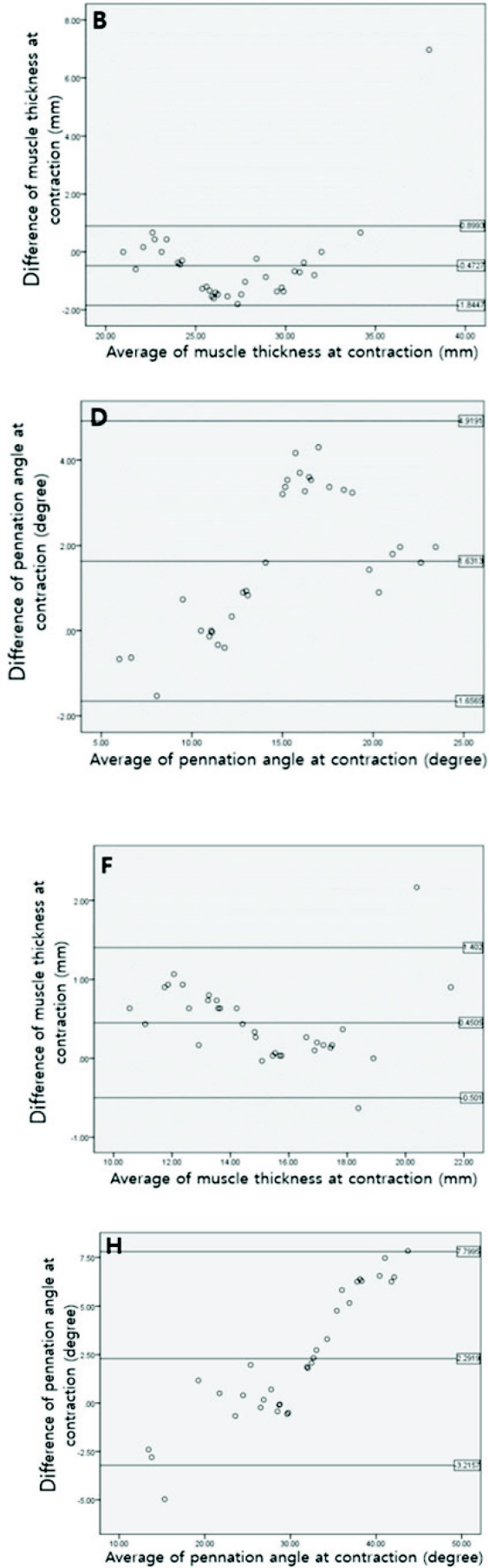

Figure 3. Bland-Altman plots illustrating the difference of ultrasound image for tibialis anterior (A-D) and medial gastrocnemius $(\mathrm{E}-\mathrm{H})$ between examiners 1 and 2 for inter-rater reliability.
Moreover, MT and PA at the MGCM assessed with the hands-free fixed probe showed excellent intra-rater reliability (ICC of MGCM MT: E1=0.943-0.982 and E2=0.9840.992; ICC of PA: E1=0.968-0.994 and E2=0.973-0.994; SEM range: $0.259-0.498 \mathrm{~mm}$ and $0.325 \mathrm{o}-1.634 \mathrm{o}$, respectively) and inter-rater reliability (ICC of MT: 0.968-0.993;
ICC of PA: 0.928-0.967). The results of our study are comparable to those of excellent reliability of the MGCM measurement values using the developed probe (ICC: 0.988-0.997) in Barber et al. [26,27] and other studies on the MGCM muscle structure using a similar method [13]. However, our results indicated higher SEM for PA compared to that for MT, 
Table 4. Correlations between TA \& GCM MT and PA measurements taken from hands-free fixed probe and the conventional linear probe

$(\mathrm{N}=33)$

\begin{tabular}{|c|c|c|c|c|c|c|}
\hline \multirow[b]{2}{*}{ Examiner } & \multicolumn{3}{|c|}{ TA (MT/PA) } & \multicolumn{3}{|c|}{ MGCM (MT/PA) } \\
\hline & $\begin{array}{l}\text { Pearson's correlation } \\
\text { coefficient }(\mathrm{r})\end{array}$ & $p$-value & $r^{2}$ & $\begin{array}{l}\text { Pearson's correlation } \\
\text { coefficient }(r)\end{array}$ & $p$-value & $r^{2}$ \\
\hline \multicolumn{7}{|l|}{ E1 } \\
\hline $\mathrm{R}$ & $0.983 / 0.979$ & $<0.001 /<0.001$ & $0.966 / 0.958$ & $0.966 / 0.960$ & $<0.001 /<0.001$ & $0.932 / 0.918$ \\
\hline $\mathrm{C}$ & $0.949 / 0.985$ & $<0.001 /<0.001$ & $0.897 / 0.970$ & $0.951 / 0.938$ & $<0.001 /<0.001$ & $0.902 / 0.877$ \\
\hline \multicolumn{7}{|l|}{ E2 } \\
\hline $\mathrm{R}$ & $0.985 / 0.990$ & $<0.001 /<0.001$ & $0.969 / 0.979$ & $0.983 / 0.982$ & $<0.001 /<0.001$ & $0.965 / 0.963$ \\
\hline $\mathrm{C}$ & $0.974 / 0.975$ & $<0.001 /<0.001$ & $0.947 / 0.949$ & $0.983 / 0.978$ & $<0.001 /<0.001$ & $0.964 / 0.956$ \\
\hline
\end{tabular}

TA: tibialis anterior, MGCM: medial gastrocnemius, MT: muscle thickness, PA: pennation angle, E1: examiner 1, E2: examiner 2, R: rest, C: contraction.

and under contraction as compared to rest, which may be due to the higher standard deviation of PA at the MGCM under contraction.

We compared the validity of measurement of MT and PA at the TA and MGCM between the hands-free fixed probe and the conventional linear probe; our results indicated high correlation among TA measurement values by the two probes (MT: $\mathrm{E} 1=0.983$ and $\mathrm{E} 2=0.985$ at rest; $\mathrm{E} 1=0.949$ and $\mathrm{E} 2=$ 0.974 at contraction; PA: $\mathrm{E} 1=0.979$ and $\mathrm{E} 2=0.990$ at rest; $\mathrm{E} 1=0.985$ and $\mathrm{E} 2=0.975$ at contraction) and among those at the MGCM by the two probes (MT: E1 $=0.966$ and E2 $=0.983$ at rest; $\mathrm{E} 1=0.951$ and $\mathrm{E} 2=0.983$ at contraction; $\mathrm{PA}: \mathrm{E} 1=$ 0.960 and $\mathrm{E} 2=0.982$ at rest; $\mathrm{E} 1=0.938$ and $\mathrm{E} 2=0.978$ at contraction). The results of our study are comparable to those of other studies assessing validity between newly developed ultrasound devices or methods and conventional devices or methods [13,17,26,27].

The hands-free fixed probe eliminates the need to hold the probe during the measurement process by the ultrasound imaging system, and the data obtained are submitted to an built-in PC-BMW software with the capability of simultaneous measurement and image analysis. Reports have indicated that PC-BMW has excellent reliability [13,17], and PC-BMW connected to a hands-free fixed probe provides added advantage. Our study has the limitation of not conducting the measurements under dynamic conditions or activities; further study is needed to assess muscle structure in situations including dynamic performance or functional movement. Our finding suggests that the hands-free fixed probe provides excellent images for measurement of MT and PA of the TA and MGCM and is a potentially useful clinical device for measurement of muscle structure without having to hold onto the probe.

\section{Acknowledgements}

This work was supported by the National Research Foundation (NRF) grant funded by Korea government (No. NRF2018R1D1A1B07042870).

\section{Conflict of Interest}

The authors declared no potential conflicts of interest with respect to the authorship and/or publication of this article.

\section{References}

1. Iwamoto Y, Takahashi M, Shinkoda K. Differences of muscle cocontraction of the ankle joint between young and elderly adults during dynamic postural control at different speeds. J Physiol Anthropol 2017;36:32.

2. Di Giulio I, Maganaris CN, Baltzopoulos V, Loram ID. The proprioceptive and agonist roles of gastrocnemius, soleus and tibialis anterior muscles in maintaining human upright posture. $\mathrm{J}$ Physiol 2009;587(Pt 10):2399-416.

3. Maki BE, Edmondstone MA, Mcllroy WE. Age-related differences in laterally directed compensatory stepping behavior. J Gerontol A Biol Sci Med Sci 2000;55:M270-7.

4. Mueller MJ, Minor SD, Sahrmann SA, Schaaf JA, Strube MJ. Differences in the gait characteristics of patients with diabetes and peripheral neuropathy compared with age-matched controls. Phys Ther 1994;74:299-308; discussion 309-13.

5. Hertel J. Functional instability following lateral ankle sprain. Sports Med 2000;29:361-71.

6. Winter DA. Human balance and posture control during standing and walking. Gait Posture 1995;3:193-214.

7. Robinovitch SN, Heller B, Lui A, Cortez J. Effect of strength and speed of torque development on balance recovery with the ankle strategy. J Neurophysiol 2002;88:613-20.

8. de Jesus JO, Parker L, Frangos AJ, Nazarian LN. Accuracy of MRI, MR arthrography, and ultrasound in the diagnosis of rota- 
tor cuff tears: a meta-analysis. AJR Am J Roentgenol 2009;192: 1701-7.

9. Pillen S, van Alfen N. Skeletal muscle ultrasound. Neurol Res 2011;33:1016-24.

10. Neumann DA, Kelly ER, Kiefer CL, Martens K, Grosz CM. Kinesiology of the musculoskeletal system: foundations for rehabilitation. 3rd ed. St. Louis: Elsevier; 2017.

11. Scott JM, Martin DS, Ploutz-Snyder R, Caine T, Matz T, Arzeno $\mathrm{NM}$, et al. Reliability and validity of panoramic ultrasound for muscle quantification. Ultrasound Med Biol 2012;38:1656-61.

12. Whittaker JL, Stokes M. Ultrasound imaging and muscle function. J Orthop Sports Phys Ther 2011;41:572-80.

13. Cho JE, Cho KH, Yoo JS, Lee SJ, Lee WH. Reliability and validity of a dual-probe personal computer-based muscle viewer for measuring the pennation angle of the medial gastrocnemius muscle in patients who have had a stroke. Top Stroke Rehabil 2018; 25:6-12.

14. Van K, Hides JA, Richardson CA. The use of real-time ultrasound imaging for biofeedback of lumbar multifidus muscle contraction in healthy subjects. J Orthop Sports Phys Ther 2006;36: 920-5.

15. Yoo JS, Ha HG, Jeong JR, Ko YJ, Lee W. Physical therapist perception survey for muscle re-education through visual feedback obtained from rehabilitative ultrasound imaging. Phys Ther Rehabil Sci 2016;5:47-52.

16. Cho JE, Hwang DY, Hahn J, Lee WH. Use of real-time ultrasound imaging for biofeedback of diaphragm motion during normal breathing in healthy subjects. Phys Ther Rehabil Sci 2018; 7:95-101.

17. Jeong JR, Han JH, Cho JE, Lee W. Reliability and validity of a personal computer based muscle viewer for measuring upper trapezius and transverses abdominis muscle thickness. Phys Ther
Rehabil Sci 2016;5:155-61.

18. Hahn J, Ha HG, Lee HJ, Lim S, Lee W. The reliability of dual rehabilitative ultrasound imaging measurements for muscle co-activation. Phys Ther Rehabil Sci 2017;6:152-7.

19. DeJong AF, Mangum LC, Resch JE, Saliba SA. Detection of gluteal changes using ultrasound imaging during phases of gait in individuals with medial knee displacement. J Sport Rehabil 2018;28:494-504.

20. Arya S. Ultrasound-guided vascular access - a hands-free option. J Intensive Care Soc 2015;16:360.

21. Chandraratna PA, Vijayasekaran S, Brar P, Tzeng J. "HandsFree" continuous transthoracic monitoring of pericardiocentesis using a novel ultrasound transducer. Echocardiography 2003;20: 491-4.

22. Mah JK, van Alfen N. Neuromuscular ultrasound: clinical applications and diagnostic values. Can J Neurol Sci 2018;45:605-19.

23. Cho KH, Lee HJ, Lee WH. Reliability of rehabilitative ultrasound imaging for the medial gastrocnemius muscle in poststroke patients. Clin Physiol Funct Imaging 2014;34:26-31.

24. Mota P, Pascoal AG, Sancho F, Bø K. Test-retest and intrarater reliability of 2-dimensional ultrasound measurements of distance between rectus abdominis in women. J Orthop Sports Phys Ther 2012;42:940-6.

25. McCreesh K, Egan S. Ultrasound measurement of the size of the anterior tibial muscle group: the effect of exercise and leg dominance. Sports Med Arthrosc Rehabil Ther Technol 2011;3:18.

26. Barber L, Barrett R, Lichtwark G. Validation of a freehand 3D ultrasound system for morphological measures of the medial gastrocnemius muscle. J Biomech 2009;42:1313-9.

27. Barber L, Barrett R, Lichtwark G. Validity and reliability of a simple ultrasound approach to measure medial gastrocnemius muscle length. J Anat 2011;218:637-42. 